\title{
Jonathan Schlesinger
}

A World Trimmed with Fur: Wild Things, Pristine Places, and the Natural Fringes of the Qing Rule. Redwood City (CA): Stanford University Press. 2017. 288pp. IS BN 978-0804799966 (hardback) 65 UsD.

Much of the recent scholarly literature on environmental issues in Inner Asia has been focusing on the issue of environmental degradation as a self-evident issue of concern, sometimes presented with dramatic overtones. There has been very little critical interrogation of the ideas related to the environment and its degradation in this part of Asia (one significant exception is the work of Humphrey and Sneath 1996, 1999). Jonathan Schlesinger's book is an important contribution to problematising environmental issues from the vantage point of critical environmental history. The stated aim of the book is to use Manchu and Mongolian sources in order to investigate the environmental history of China during the Qing rule. Given that this topic has been investigated mostly from the vantage point of Chinese records, the views from the periphery of the Qing Empire, recorded in Manchu and Mongolian archives, offer different perspectives about both the nature of environmental problems, and their political interpretation at the time. To 'the view from Beijing' (the title of Chapter One), therefore, the author wants to juxtapose and contrast the view from the frontiers. He does so by following three particular types of commodities and their associated environmental problems: Manchurian pearls, Mongolian wild mushrooms, and furs from the borderlands with Russia. Each of these case studies discusses two sets of phenomena: changes in the environment, and changes in the ideas about the environment. It traces the mounting sense of an environmental crisis (or perhaps multiple crises) as documented by petitions and other kinds of official documents being sent to Beijing in large numbers during the period 1760 to 1830 . At the same time, the book also documents the evolution of environmental attitudes and ideas prominent in the centres of power, and the political nature of the discourses related to environmental degradation. Thus, not only do we learn about various fur-bearing animals (e.g. foxes, sables, squirrels) vanishing from the forests, mussels not producing pearls, and uprooted steppes, we also get insight into how the colonial visions of 'pristine nature' were deployed in order to 'purify' nature on the steppe and in the forests. The resulting conclusion, central to the book, is that the Qing Empire did not merely preserve nature, it invented it.

The book is organised into four main chapters, an Introduction, and a Conclusion. The material in the four main chapters is organised around three case studies: the exploitation of fresh-water pearls in Manchuria, the harvesting of wild mushrooms on the Mongolian steppe, and the collection and 
trade of furs in the borderlands between Mongolia and Russia. An important background canvas (Chapter One) is laid out before the three cases are discussed. This chapter presents, a cultural ecological analysis of environmental ideas during Qing rule, often portrayed in contrast to the Chinese ideas that preceded them. There is much detail given to practices regarding wild ingredients, species of game being hunted and consumed, as well as to fur fashions. Interestingly it also documents how ideas of Manchu rulers about purity, the 'natural', and their imagined history and identity (among others as furwearers), had spread to the streets of Beijing by the late eighteenth century. This is an excellent, inquisitive analysis of the 'cultural' in a rather fluctuating historical period that gives great insight into attitudes towards the environment. If there is any critique to be made, it is one common to cultural ecological accounts: the environment is perceived as influencing the people inhabiting it to such an extent that the patterns of sociality (institutions, customs) are 'attuned' to it. Much of the book contradicts this view, but it is still perceivable in this chapter as an attractive explanatory device.

Chapters Two to Four present in great detail the exploitation of the three commodities mentioned above. We learn from Manchu-language archives about the establishment of pearl fisheries, their decline, and efforts to 'nurture' them. The story is masterfully linked to ideas about the Manchu homeland and the re-casting of Manchuria as a productive space, rather than the previous 'wild borderland' vision from Beijing.

We also get a detailed glimpse of the 'great mushroom rush' to the Mongolian steppes (an event conspicuous in Chinese sources by its absence) of the $1820 \mathrm{~s}$. Combining an impressive array of sources (from Memorials to the Throne, complaints to local authorities, confessions of mushroom pickers), Schlesinger paints a rich picture of the wild mushrooms as commodities, the perceived environmental crisis, and a new politics of nature in Mongolia. The latter is a good example of the major contribution of the book: the topic of mushroom harvesting was intimately bound up with the contestation and reinforcement of territorial and jurisdictional boundaries. This territorialisation involved the access of Chinese merchants to Mongolian banners (including the Qing efforts 'to protect the Mongol character of the banners'), and the general institutionalisation of trade in the region. Importantly, this case study illustrates also how ideas about 'purifying the land' by repatriation of trespassing mushroom pickers, was in fact part of a larger political project of building authority.

Finally, the last commodity investigated in this detailed environmental history is fur. Against the background of complaints sent to Beijing about difficult hunting, scarce animals, and corruption, there is a more detailed political ecological story at play. The author proceeds methodically to uncover various 
complex connections between the Qing colonial power and Tannu Uriankhai hunters in northwest Outer Mongolia, as well as connections of Inner Asian fur traders with global networks. What we learn, in the end, is that just like in the case of pearls and mushrooms, this commodity was an integral part of the Qing process of border making, authority building, and contestations thereof; a complex political and environmental history.

Overall, the book is very well structured and documented, with the central ideas made visible throughout the text. It is undisputedly a valuable addition to building a critical view of environmental ideas in the region. There are, nevertheless, some noticeable areas in which the argument could be made stronger.

One is the treatment of environmental change (mostly degradation), which for the most part in the book relies on the official records and the complaints made to officials. The weakness here is that these data are very often taken at face value, as trustworthy evidence for degradation. Since the book convincingly documents the political nature of environmental discourses, and in the absence of other sources of information about the environment, makes this assumption questionable. For instance, collapses or dramatic reductions in pearl mussels, mushrooms, or fur animals may have had causes more related to larger environmental change (e.g. climate change or, variation) rather than over-exploitation. This is especially true of pearl mussels, which are notoriously sensitive to minute changes in their ecosystems. The methodology could have also been extended toward a material environmental history that could draw on climatology, botany, or physiology.

Secondly, there is surprisingly little use of sources that could document local people's practices of resource extraction. Such practices are usually documented in environmental history studies whereby historical archaeology is often combined with maps and microhistory in order to tell detailed stories. Finally, although the author does try to place this environmental history in a wider context, there is much greater scope for connecting the work herein with famous work documenting colonial re-imaginings of nature in colonised regions, from related disciplines such as political ecology and environmental anthropology. I for one would have liked to read some reflections about how (if at all) the story presented herein is an example of 'the work of purification', or if the Qing were essentially performing the 'work of mediation' between human culture and nonhuman nature that Latour (1993) envisioned.

\section{Andrei Marin}

Norwegian University of Life Sciences (NMBU), Ås, Norway amarin@nmbu.no 


\section{References}

Humphrey, C. \& Sneath, D. (1996). Culture and Environment in Inner Asia. Cambridge: The White Horse Press.

Humphrey, C. \& Sneath, D. (1999). The End of Nomadism? Society, State and the Environment in Inner Asia. Cambridge: The White Horse Press.

Latour, B. (1993). We Have Never Been Modern. Cambridge (MA): Harvard University Press. 